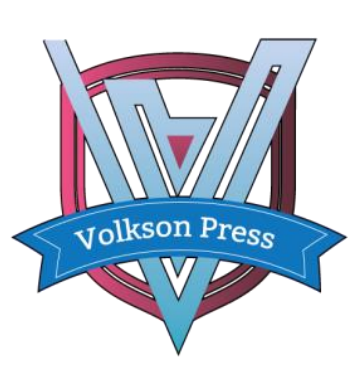

Contents List available at VOLKSON PRESS Economics \& Management Innovations(EMI)

DOI : http://doi.org/10.26480/icemi.02.2018.18.20

ISBN: 978-1-948012-14-0

\title{
A POLITICAL FAILURE MAY HAVE POSITIVE ECONOMIC EFFECTS: THE SELF- STRENGTHENING MOVEMENT
}

\author{
Lishan Zhang \\ School of Economics and Management, Tongji University Siping Road, Shanghai, China. \\ *Corresponding Author Email: lishanzhang3@hotmail.com
}

This is an open access article distributed under the Creative Commons Attribution License, which permits unrestricted use, distribution, and reproduction in any medium, provided the original work is properly cited.

\section{ARTICLE DETAILS}

\section{Article History:}

Received 26 June 2018 Accepted 2 July 2018

Available online 1 August 2018

\section{ABSTRACT}

This paper provides analysis and approaches on viewing the Self-Strengthening Movement in an economic perspective, combined with peer researches on the Movement itself and a counterpart, the Meiji Restoration. Meanwhile, this paper tries to offer enlightenments for modern researches on the economic effects of historical events.

\section{KEYWORDS}

The Self-Strengthening Movement, political failure, economic results.

\section{INTRODUCTION}

This paper tries to carry out empirical and statistical research on the economic results of the Self-Strengthening Movement. Overall speaking, either in China or in the west, the Movement can generally be called a failure. The most often mentioned achievement of the Movement may only be that it helped Qing to suppress the Taiping Rebellion. But the uselessness and inefficiency of the Movement has adequate evidence. Smith (1976) believed that, to eliminate dependence on foreigners and to build China's own military capabilities were the twin goals lay at the heart of the Self-Strengthening Movement [1]. However, repeated humiliations suffered at the hands of foreigners, along with many lost wars and cowardly concessions since the Opium War, lasted until the early $20^{\text {th }}$ century. In fact, China's failure in the Sino-Japanese War in 1895 is widely considered to be the sad ending of the Movement.

However, there are three good reasons to study the economic effects or the economic relevance of the Self-Strengthening Movement. Firstly, this will offer a brand-new position from which we assess a historical event instead of criticizing it based on the most obvious consequences. This may enable us to capture a clearer relationship of economy and military and politics in a complicated situation. Secondly, the study may be informative on present countries' making reform policies, especially in terms of the process of reform as well as the emphasis such as enterprises' type, nature of businesses and government interference. For the reasons mentioned, it would be a worthwhile and meaningful project.

\section{LITERATURE REVIEW}

\subsection{Peer research on the impact of the Movement}

This part deals with the existing works on the economic effects of the Movement. Kennedy (1976) pointed out that, certain Chinese leaders urged the adoption of selected elements of foreign civilizations, as a means to increase the wealth of the empire [2]. Although this movement stressed military and diplomatic modernization, it was not limited to this. Kucha and Llewellyn (2015) analyzed that among the projects established at that time, the majority of successful ones were managed and funded by provincial governments or private business interests [3]. This is closely related to the economic internal structure of enterprises. The influences were surely not that outstanding in that era but would manifest themselves later gradually.

There are some views on the direct effects on economy. Hacker (1977) believed that some Chinese officials came to see, reluctantly, the unbreakable chain that led from firearms and ships to coal mines, iron foundries, and railroads; from military technology to industrialization; from the weapons of the West to Westernization [4]. In other study, researchers asserted that the Movement brought about semi-capitalism, a new-born thing never seen in Chinese history and the most progressive factor at that time [5]. In a certain sense, the Movement is the feudal China's transition to "semi-capitalism" stage. Therefore, its progressive side cannot be ignored of. Although historians and economists have paid certain attention to the economic side, no research has been done to investigate the degree of effects and how economy got affected based on real data and combined with the series of measures Qing took in different fields.

\subsection{Peer research on the Meiji Restoration case}

Rousseau (1998) did a statistical research on the question whether financial factors played a leading role in the rising investment rates and per capita incomes that characterized Japan during 1880-1913 [6]. He focused on the finance sector and tested whether financial reforms helped to boost the economic development of Japan.

Specifically, Rousseau constructs new annual series from available historical statistics that reflect both the extent of formal intermediation in Japan and the growing importance of publicly held corporate securities and links these series to the time paths of real per capita estimates of output, gross investment, and private investment, as well as investment's share in output. And based on the specific policies Japan carried out during the Restoration, this paper mainly employs two measures of financial development. One is an estimate of the total assets of financial intermediaries (FIA) and the other one is broader aggregate appends nonintermediary holdings of corporate and bonds to FIA. Besides, this paper used an instructive mathematical method, vector auto regression (VAR). 


\section{OBJECTIVE}

The specific question this project will help to work on is: did the economy get positively affected by the Movement during and after it? This is to estimate the economic impacts of the Movement and its significance, if data permits, to obtain the pattern. There has been an agreement that the Movement is indeed a political failure, but about its economic efficiency, none popular conclusion was reached. To combine the technological and educational inputs with the economic output may be of some help.

As for the period we look at, the Movement is defined to last from 1861 to 1895. So the events that could have influenced the economy should be in this period. But the resulting impacts should not be limited to that. Tseng \& Wu (2013) pointed out the Movement is the beginning of an agonizing process of awakening and protest that lasted nearly a century [7].

Firstly, the variable on the left-hand side should be set down. From the existing works, most used the data on prices, imports and exports to evaluate the trend of change during that period. But to evaluate the total performance of a nation during some time, the most appropriate one may still be GDP or GNP since they catch the output and prices simultaneously. Plus, industrial output may also be an ideal choice since industrialization is exactly a point worth attention in the topic of the Movement.

As for the variables on the right-hand side, events or measures that have influence on economy can't be neglected. The industries that were set up should come first. It is quite a major force in industrious output and it is a reflection of the change of type of enterprises at that time. The output and capital of industries can both show the condition or the development of industries with the influence of the Movement.

Besides, education reforms should be taken into account. Others researchers found that students sent abroad later came back and many of them became the directors of the factory or the persons in charge [8]. On the contrary, foreign teachers coming to those schools founded during the Movement may also play a part in spreading Western culture and technologies. Additionally, those translated works ought to be considered. There is a general agreement that works brought modern knowledge to China. But statistical evidence is needed to prove that it helped production. Meanwhile, railway constructions were also of vital importance [9]. It was a crucial factor for transportation and commodity logistics.

\section{DATA}

Maddison Project has adequate information on the macroeconomic indicators of China. Some papers mentioned above also offer different types of data. According to the objective and Rousseau's approach, data both from Chinese papers and from researches in the west are collected.

Table 1: Table of Variables and Sources

\begin{tabular}{|l|l|l|}
\hline Variable & Source & $\begin{array}{l}\text { Period } \\
\text { covered }\end{array}$ \\
\hline GDP & $\begin{array}{l}\text { Maddison (2003); } \\
\text { Liu and Yeh (1965) }\end{array}$ & $1820-1937$ \\
\hline $\begin{array}{l}\text { The number of factories } \\
\text { (official) }\end{array}$ & Yan (1955) & $1872-1911$ \\
\hline $\begin{array}{l}\text { The number of factories } \\
\text { (private) }\end{array}$ & Yan (1955) & $1872-1911$ \\
\hline Railway mileage & Yan (1955) & $1876-1937$ \\
\hline Amount of returning students & Xia (1996) & $1862-1893$ \\
\hline Amount of translated works & Li (2012) & $1873-1899$ \\
\hline Amount of foreign teachers & Xia (1996) & $1868-1893$ \\
\hline
\end{tabular}

\section{APPROACH}

$Y=\beta 0+\beta 1 X 1+\beta 2 X 2+\beta 3 X 3+\beta 4 X 4+\beta 5 X 5+\beta 6 X 6+\varepsilon$

Y: GDP

$\mathrm{X}_{1}$ : The number of factories (official) \& $\mathrm{X}_{2}$ : The number of factories (private)

$\mathrm{X}_{3}$ : Railway mileage
$\mathrm{X}_{4}$ : Amount of returning students

$\mathrm{X}_{5}$ : Amount of translated works

$\mathrm{X}_{6}$ : Amount of foreign teachers

The equation above is a typical econometric model. The most widely used method may be OLS - to run regression of Y on all the Xs and obtain the estimators.

Rousseau's approach will serve as a reference here. And the model we study turns to this one.

$\mathrm{Yt}=\mathrm{c}+\Pi 1 \mathrm{Yt}-1+\Pi 2 \mathrm{Yt}-2+\ldots \ldots+\Pi \mathrm{kYt}-\mathrm{k}+\mathrm{ut}$

( $Y t$ is a time series column vector with $n \times 1$ order;

$\mathrm{C}$ is a constant term column vector with $\mathrm{n} \times 1$ order;

$\Pi 1$...

ut is random error column vector with $\mathrm{n} \times 1$ order; $\mathrm{k}$ is the lag order)

The traditional method of economic measurement is based on economic theory. However, economic theory is often insufficient to provide a rigorous account of the dynamic linkages between variables, especially for a series of seemingly non-related variables here, such as GDP and amount of foreign teachers [10]. And also the lagged effect is not taken into account appropriately. In this case, VAR is ideal.

Vector auto regression (VAR) is a stochastic process model used to capture the linear interdependencies among multiple time series what are exactly what we have here. Vector Auto regression (VAR) is often used to predict interconnected time-series systems and to analyze the dynamic effects of random disturbances [11]. Besides, Introducing the lagged value may help to obtain a more correct model. For instance, the longer the returning students stayed the more contribution or the greater contribution they would make to the economy.

Additionally, the variables we use here are also likely to mutually relate to others. For example, the amount of returning students may contribute to the amount of translated works. The number of factories will affect railway mileage since they would produce the raw materials. And the railway development would in turn help factories. How to determine the lagged value $\mathrm{k}$ is of vital importance. Usually there are several ways: Akaike Information Criterion (AIC), Schwarz Criterion (SC) and Bayesian Information Criterion (BIC). When the results of the several approaches differ, the smallest one should be chosen

However, before the tests, some adjustments are meant to be taken for the data. What VAR firstly needs is that all the variables have the same time coverage and this is the fundamental of next steps. For example, if X1 is measured from 1872 - 1936, then all the other variables should also be from 1872 - 1936. That is to say we need to apply statistical methods to fill the gaps between years and work out solutions to obtain more data than present.

Only after this step above can we move on. Firstly, we need to test whether the data are stationary. If we omit this step and directly go to OLS, it is very likely to lead to spurious correlation. Often there are several ways to test, but the most widely used one is unit root test. If the tests are unable to reject the null hypothesis of a unit root for a series in levels, yet reject the null after differencing, it is appropriate to treat the series as nonstationary in subsequent modeling [12]. It is recommended that the log transformation is applied to all series to render deterministic components in the data more nearly linear.

Next, which test to take next is up to the result of the stationarity test. When the test shows the data is non-stationary (that is, there is a unit root), and each sequence is the same order of co-integration, to further determine the existence of co-integration between variables, we need cointegration test: Johansen test [13]. This is to test for stationary long-run relationships between the macroeconomic indicators and measures of industrial and education development. Why we use it here and the meaning behind the use is that, regardless of the special political environment, how the industry, economy and education interact and coordinate with each other is still very important and instructive for 
today's policy [14]. So to seek a long-term relationship, if successful, can be a good lesson that countries can learn nowadays. Here the full information maximum likelihood approach of Johansen is used to identify the number of stationary long-run relationships. Each system is modeled as a vector auto regression of the form below.

$\Delta \mathrm{xt}=\mathrm{u}+\Sigma \mathrm{Ti} \Delta \mathrm{xt}-\mathrm{I}+\Pi \mathrm{xt}-\mathrm{k}+\mathrm{et}$

( $\Sigma$ is the sum from $\mathrm{i}=1$ to $\mathrm{i}=\mathrm{k}-1$; $\mathrm{k}$ is the lag order)

$\mathrm{Xt}$ is a vector containing the seven potentially endogenous variables and $\mathrm{k}$ is adequately large both to capture the short-run dynamics of the underlying VAR and to generate residuals that approximate the normal distribution. The lag order which is mentioned above for each system is chosen with a series of nested likelihood ratio tests. The Johansen methodology tests whether the matrix is of less than full rank via the trace and maximum eigenvalue statistics. The null hypothesis for Johansen test is that at most one co-integrating vector provides evidence of a single longrun relationship [15]. Whether to reject it needs the specific tests based on our data. If the result shows there is no co-integration, indicating there's no long-term stable relationship. We can still construct a VAR model and do stability analysis based on AR root chart analysis to figure out the shortrun dynamic model [16]. If all unit roots are less than 1, VAR model is stable and is ready to run pulse analysis and Variance decomposition. For a VAR model, stability means that, when a pulse impulse is applied to an equation in the VAR model, over time the impact will disappear. And a stable VAR model will not be affected and change itself in the long term. Variance decomposition is very often used in applied statistics to determine whether a change in $\mathrm{Y}$ can be statistically significantly explained by the change in Xs [17].

If the data is stationary according to the stationarity test, to further examine the causal relationship between variables, we can use Granger causality test. Alternatively, stationary data can also go to OLS regression, but we won't go to details about this popular method here. The causal relationship in Granger test is not the relationship that we usually understand, but the relationship that change of $y$ can be effectively explained by the earlier change of $\mathrm{x}$. And the $\mathrm{x}$ is called the "Granger reason" $[18,19]$. The test model can be written as

$\mathrm{Yt}=\Sigma \alpha \mathrm{iYt}-\mathrm{i}+\Sigma \beta \mathrm{iXt}-\mathrm{i}+\mathrm{u} 1 \mathrm{t}$

$\mathrm{Xt}=\Sigma \alpha \mathrm{iXt}-\mathrm{i}+\sum \beta \mathrm{iYt}-\mathrm{i}+\mathrm{u} 2 \mathrm{t}$

$\mathrm{H} 0: \beta 1=\beta 2=\ldots=\beta \mathrm{p}=0$

( $\Sigma$ is the sum from $\mathrm{i}=1$ to $\mathrm{i}=\mathrm{p}$ )

What can make these tests more feasible and the results more convincing? The answer is fewer variables but in a longer run. If some advanced methods can integrate some of the variables here into two or three indexes, the process of tests will be simpler. And if we can take those impacts of lost wars and corruption in the court during that time and then index them, the model would be more complete and may be more in line with the historical performance. However, if data are not that available, we can also add dummy variables to solve this. As for how to take these tests practically, STATA, Eviews and the R Project can all be alternative software.

\section{REFERENCES}

[1] Smith, R.J. 1976. Foreign-Training and China's Self-Strengthening: The Case of Feng-huang-shan, 1864-1873. Modern Asian Studies, 10 (2), 195223.
[2] Kennedy, T.L. 1973. Self-Strengthening: An Analysis Based on Some Recent Writings. Late Imperial China, 3 (1), 3-35.

[3] Kucha, G., Llewellyn, J. 2015. The-Self Strengthening Movement. Retrieved from: Alpha History http://alphahistory.com/chineserevolution/self-strengtheningmovement/.

[4] Hacker, B.C. 1977. The Weapons of the West: Military Technology and Modernization in 19th-Century China and Japan. Technology and Culture, 18 (1), 43-55.

[5] Worden, R.L., Savada, A.M., Dolan, R.E. 1987. China: A Country Study. Retried from: http://countrystudies.us/china/17.htm on 5 December 2017.

[6] Rousseau, P.L. 1999. Finance, investment, and growth in Meiji-era Japan. Japan and the World Economy, 11 (2), 185-198.

[7] Tseng, W.S., Wu, D.Y.H. 2013. Chinese Culture and Mental Health. Academic Press, London.

[8] Maddison, A. 2007. Chinese Economic Performance in the Long Run, 2nd edn. OECD Publishing, Paris.

[9] Elman, B.A. 2004. Naval Warfare and the Refraction of China's SelfStrengthening Reforms into Scientific and Technological Failure. Modern Asian Studies, 38 (2), 283-326.

[10] Fan, H. 1988. From "Gezhi" to "Science". Journal of Dialectics of Nature, 10 (55), 39-50.

[11] Jia, G. 2014. Trying not to Repeat the Mistake of Westernization Movement in Independent Innovation Strategy. Journal of Tianjin University of Commerce, 34 (1), 4-7.

[12] Kuo, T. 1978. Self-strengthening: the pursuit of Western technology. In The Cambridge History of China: Part 1 (Fairbank J.K.). Cambridge University Press, Cambridge, 10, 1800-1911.

[13] Li, Y. 2015. Westernization Movement and Chinese Early Agricultural Modernization. Journal of Xinzhou Teachers University, 31 (6), 82-85.

[14] Ma, D. 2005. Shanghai-Based Industrialization in the Early 20th Century: A Quantitative and Institutional Analysis. Retrieved from: http://eprints.lse.ac.uk/22473/ on 10 December 2017.

[15] Pong, D. 1994. Shen Pao-chen and China's Modernization in the Nineteenth Century. Cambridge University Press, Cambridge.

[16] Qu, J. 2016. Self-Strengthening Movement of Late Qing China: An Intermediate Reform Doomed to Failure. Asian Culture and History, 8 (2), 148-154.

[17] Shambaugh, D.L. 2008. China's Communist Party: Atrophy and Adaptation. University of California Press, Berkeley.

[18] Su, L. 2014. Westernization Movement and the Starting-point of Chinese Modernization. Journal of Gansu Normal Colleges, 19 (3), 118120 .

[19] Yang, A. 2017. A Comparison Study on Modernization in the Meiji Restoration and the Self-Strengthening Movement. Retrieved from: https://lup.lub.lu.se/student-papers/search/publication/8904933 on 10 December 2017. 